\title{
Implicit-explicit gradient of nondual awareness or consciousness as such
}

\author{
Zoran Josipovic, PhD \\ New York University \\ New York, NY \\ Nonduality Institute \\ Woodstock, NY
}

\begin{abstract}
Consciousness is multi-dimensional but is most often portrayed with a 2-D map that has global levels or states on one axis, and phenomenal contents on the other. On this map, phenomenal content is conflated with awareness itself, which contributes to ongoing difficulties in the scientific understanding of consciousness.

Previously (Josipovic 2014, 2019; Josipovic and Miskovic, 2020) I have proposed that consciousness as such, or nondual awareness - a basic non-conceptual, non-propositional awareness in itself free of subject-object fragmentation, is phenomenally, functionally and neurobiologically, a unique kind that cannot be adequately specified by a 2-D map of levels/modes and contents.

Here, I propose an implicit-explicit gradient of nondual awareness to be added as the third dimension on z-axis. an axis to the 2D map of consciousness. Alternatively, within the multi-dimensional state space model of consciousness, nondual awareness can be specified by several vectors, each representing one of its properties.

I explore how including the implicit-explicit gradient of nondual awareness as an additional axis clarifies certain features of everyday dualistic experiences and is especially relevant for understanding the unitary and nondual experiences accessed via different contemplative methods, mind altering substances, or spontaneously. I discuss the relevance of this for current theories of consciousness.
\end{abstract}




\section{Introduction}

I have previously proposed that consciousness as such, or nondual awareness - a basic non-conceptual, non-propositional awareness in itself free of subject-object fragmentation, is phenomenally, functionally and neurobiologically, a unique kind that cannot be adequately specified by a 2D map of state-level and content (Josipovic 2014, 2019; Josipovic and Miskovic 2020).

Here, I propose an implicit-explicit gradient of nondual awareness to be added as the third dimension to the 2D map of consciousness. This gradient informs about the degree to which nondual awareness is manifest in any experience, independent of the specifics of global state or local content. Alternatively, within a multi-dimensional state-space model of consciousness, nondual awareness can be specified by several vectors, each representing one of its properties, in which case the proposed z-axis would be their summation vector.

I will also explore how including the implicit-explicit gradient of nondual awareness as an additional axis clarifies certain features of everyday dualistic experiences and is especially relevant for understanding the unitary and nondual experiences accessed via different contemplative methods, mind altering substances, or spontaneously. I discuss the relevance of this for current theories of consciousness.

For the sake of clarity and brevity this discussion is organized in top-down manner, emphasizing theoretical implications over empirical details of first-person accounts and neuroscience studies. However, ideas presented here are not merely normative. Phenomenal descriptions come from texts of various traditions, which form a body of evidence about centuries of experiences with various contemplative practices, and from increasingly large numbers of contemporary practitioners of meditation world-wide. (Metzinger 2020; Tang and Holzel 2015; Woods et al. 2020). In addition to newly developing methods of assessing participants' experience, neuroscience studies have significantly increased our understanding of consciousness in contemplative and altered state experiences (Ataria et al. 2015; Hanley et al. 2018; Lente and Hogan 2020; Lutz and Thompson 2003; Petitmengin et al. 2019; but see Krageloh ).

A number of perennial issues in the discourse on nondual awareness related to levels of discourse, limitations of language, and conflating of nondual awareness with effects it has on states and contents have been discussed extensively elsewhere and will not be revisited here. (Dunne, 2015; Josipovic, 2016, 2019; Metzinger 2020).

\section{Extracting the nondual awareness from states and contents}

Human consciousness is exceedingly complex and representing it by a map, or a model, is challenging and, at best, incomplete. The most commonly used map decomposes consciousness into two dimensions: the global state or level which indicates a degree of alertness on one axis, and the local content indicating a degree of vividness and richness or 
amount of perceptual, affective or cognitive content (Laureys 2005; Boly et al., 2012). Their neural correlates are, respectively, the reticular activating system and its limbic projections, and the thalamo-cortical system, (Aru et al. 2019; Koch et al. 2016; Storm et al. 2017).

Mapping consciousness in this way has been useful, especially in the field of neurology, but, as many have noted, rather incomplete (Bayne et al., 2016; Overgaard and Overgaard 2010). For example, features central to altered states of consciousness cannot be specified by a single dimension or level and require other dimensions (Carter and Bayne 2019; Milliere et al 2018). Contents too can be seen as a summation of a number of other dimensions or factors, such as subjective sense of specificity, vividness and intensity (Fazekas et al 2020).

Representing consciousness by multi-dimensional state-space models better captures many of its nuances and complexities. (Berkovich-Ohana and Glicksohn 2014; Fazekas and Overgaard, 2016; Milliere et al. 2018). However, this too is not without issues. The many possible dimensions can rapidly make a model computationally unmanageable. Additionally, merely labeling a feature, does not necessarily make it a genuine dimension of consciousness. From the perspective of the 2D map, each of its axis can be seen as a summation of various related dimensions of a multi-dimensional state-space model (Bayne et al 2016).

An intuitive fact is that the 2-D map of consciousness lacks the third dimension, or zaxis. Various features of consciousness or conscious experience have been proposed as possible z-axis, such as, self and self-awareness (Hanoğluet al 2013), subjective report of level or state (Bachman 2012), and the connection with external environment (Carhart-Harris et al. 2017). For the present discussion, the main issue with the 2D map can be seen as the conflation of awareness itself with global state and local content, which contributes to ongoing difficulties in the scientific understanding of consciousness (Josipovic and Baars, 2015; Josipovic and Miskovic 2020).

Nondual awareness or consciousness as such can be differentiated from global states of consciousness. A global state can be changed by directly or indirectly manipulating the level of arousal in the brain (Pal et al. 2019; Tanabe et al. 2020). Given the necessary minimum level of arousal, a state can be altered independently of awareness. Many meditation techniques can alter the global state by either reducing or enhancing arousal, while awareness remains present more or less unchanged (Amihai and Kozhevnikov 2014). Conversely, there are cases of vegetative states of bare wakefulness without awareness being present (Boly et al., 2012). Further examples of dissociation between awareness and global state are the instances of attaining lucidity during REM and NREM sleep (Dressler et al. 2012; Thompson 2014; Voss et al.2014; Windt 2015), and the NDE experiences (Martial et al. 2020). In those states, awareness can be present with very low level of arousal. Awareness can also be present in hypomanic states of high arousal, such as those induced by psychedelics and other drugs (Milliere et al. 2018). Thus, awareness is differentiable from global states of consciousness. Within certain lower and upper bounds, the level of arousal does not specify awareness itself. 
Awareness can also be differentiated from local contents. Qualia, or a subjective experience content, always have two aspects: specifics that characterize that content, and awareness (Koch et al. 2016). These can be compared to an image in the mirror and the mirror itself (Josipovic 2016). Also, awareness can be present independent of the amount of content, with a large amount of content during full normal wakefulness, or with a minimal content as in lucidity during NREM sleep (Josipovic and Miskovic, 2020; Metzinger, 2020). Thus, awareness and content are differentiable. Treating awareness and contents as differentiable has been accused of leading to the dead-end of cartesian dualism (Dainton, 2002). However, this objection does not apply here because nondual awareness is inherently without the subjectobject structuring and abides non-dually with content.

This awareness can then be represented on the z-axis, as the implicit-explicit gradient that informs about the degree to which nondual awareness is manifest in an experience. Though it can be experienced and conceptualized as distinct from states and contents, it interacts with them, similarly to the way states and contents interact.

\section{Nondual awareness - consciousness as such}

Human consciousness can be thought of as the capacity for experiencing and knowing, and perhaps most importantly, as the capacity to know that we know (Baars et al. 2013; Block 2007; Koch et al. 2016; Lamme 2015; Rosenthal 2012; Brown et al. 2019). As conscious experience, it is defined by global states and local content (Storm et al. 2017; Koch et al. 2016). The conscious-unconscious dichotomy can be seen as a mode in which states and contents can appear, determined by global and local excitation and inhibition in the brain (Buszaki 2006; Mashour and Hudetz 2018; Josipovic 2019).

Among different ways of knowing and experiencing, the two are radically different: an indirect way, mediated by mental representations and processes that operate on them (Shea 2018), and a more direct way, without mediation by mental representations, via nondual awareness or consciousness as such (Dunne 2015; Thompson, 2021; Josipovic 2014; 2019). In this sense, consciousness as such is a type of knowing, a basic non-conceptual, nonpropositional awareness, without reified dualistic structuring of knowing and experiencing into subject-object, self-other duality that characterizes the representational knowing. Hence, it is termed nondual awareness (Josipovic 2010, 2014; Dahl 2015).

These two types of knowing interact, but the direct one is usually obscured by the coarser indirect one. When obscured or replaced by mental representations, nondual awareness is present only implicitly as the background conceptual knowing that one is conscious. When it is explicitly present, it knows itself as that which is aware inherently, and as the aware space within which conscious states and contents occur. (Josipovic, 2019).

According to the non-representational reflexivity (NRR) theory of consciousness (Josipovic, 2019; but see Peters 2013 for representation-based version of the same), the central 
property of nondual awareness is its inherent capacity to know that it knows, without the mediation by mental representations. This direct non-representational reflexivity is inherent in consciousness as such as its main property, and is non-transitive, without subject-knowingobject structure (Anspal 2005; Fasching 2020; Higins 2011; Laish 2015; MacKenzie 2015; Williams 2000). Thus, this is neither the reflective nor the pre-reflective consciousness as usually understood, as these are based on mental representations (but see Dreyfus in Thompson 2021 for an update on pre-reflective). The inherent reflexivity of nondual awareness, also termed as self-knowing or self-recognition (Williams 2000; Kshemaraja and Singh 1990) can become activated and awareness recognizes itself, either when isolated from other phenomenal content during a minimal phenomenal experience, or when present with full phenomenal content during ordinary waking state (Josipovic 2019; Josipovic and Miskovic, 2020; Metzinger, 2020; Dunne Thompson Schooler, 2018). When this capacity is activated, nondual awareness will here be termed explicit nondual awareness.

When isolated from all other phenomenal content and explicit, as can occur in the full meditative absorption or in the instances of luminosity during NREM sleep, pure nondual awareness appears as an open, empty cognizance, aware and present, but without any thoughts, emotions or perceptions, without a sense of body, orientation, time or the usual sense of self (Thompson 2014; Travis and Pearson, 2000; Metzinger 2020; Forman 1998; Josipovic, 2019).

When explicitly present during ordinary waking experience, nondual awareness is experienced as simultaneously transcendent and immanent in conscious states and contents. Transcendent, as the silent aware space that pervades and encompasses the entire conscious experience, one's entire perceptual bubble, and immanent, as that out of which everything is made, the way water in a glass is both the medium in which ice cubes float, and the substance out of which they are made (Josipovic, 2019, Josipovic and Miskovic 2020). This is the meaning of the term nonduality as understood here, rather than its more literal meaning indicating an absence of content or an absence of self-specifying processes.

Nondual awareness has been compared to a mirror, while phenomena that appear to it have been compared to reflections in the mirror (Josipovic, 2016). Its manner of knowing phenomena can be described as mere reflecting or registering, without categorization or further conceptual elaboration, that is, without associating, evaluating, forming decisions, or taking itself as a reified subject that knows phenomena as reified objects (for a detailed discussion, and disambiguation from bare non-conceptuality, see Thompson 2021). Enaction, simulation and resonance, or a combination of these, have been proposed as mechanisms of the non-representational knowing, and may be mechanisms of nondual awareness as well. (Gallese 2005; Hunt and Schooler 2019; Zahidi 2014) 


\section{The central precuneus network for nondual awareness}

A neural correlate of nondual awareness needs to be able to function relatively independently from most global states and local contents, and also serve as the aware spatial context within which conscious states and contents can occur (Josipovic 2014, 2019; Metzinger 2020). A parieto-frontal cortico-cortical and thalamo-cortical network with self-sustaining dynamic regime could perform such a function. I have previously proposed that the cognitive associative central precuneus network that links the central precuneus with the (dorso) lateral prefrontal cortex (dIPFC, BA 10/46), the dorsal anterior cingulate (dACC and dmPFC, BA32, BA8) and the inferior parietal lobe (TPJ / the angular gyrus ( $r / \mathrm{l}-\mathrm{Ang}$,), fulfils the criteria for the neural correlate of nondual awareness (Margulies et al. 2009; Cavanna \& Trimble, 2006, Cunnigham and Volkov 2016; Josipovic 2014, 2019). Perhaps more than any of the major resting state networks in the brain (Buckner and DiNicola 2019), the central precuneus network overlaps or connects with other networks: with FPC in dIPFC, with DA in FEF, with VA in dACC, with DMN in inferior parietal/TPJ (Margulies, 2009), allowing it a key function in the global integration of the brain. The central precuneus network is involved directly or indirectly via its nodes in a wide variety of cognitive functions (Margulies et al., 2009), so the neural correlate of nondual awareness may be only a subset of its neurons, or a particular pattern of its connectivity, or dynamics.

The precuneus in general is a major hub of the brain organization (Cavanna and Trimble 2006; , Pereira-Pedro and Bruner, 2016; Tomasi and Volkow, 2011; Utevsky et al., 2014) and is the likely organizing core of the 'posterior hot zone' in the brain (Tononi and Koch 2015). Like other key nodes of the associative areas of the cortex, the precuneus can be involved in a number of perceptual, motor, affective and cognitive functions (Andrews-Hanna et al., 2010; Boly et al., 2012; Cavanna and Trimble, 2006). Studies of diverse stimuli from both external and internal environments have found that increased awareness of stimuli is accompanied by increased connectivity of the precuneus to the areas processing those stimuli, pointing to the role of precuneus in awareness. (Grund et al. 2021; Mashal et al. 2014; Martial et al. 2019). Together with areas directly involved in regulating levels of arousal, the precuneus is involved in global states of consciousness. Reduction of its signal, and its decoupling from the global brain network, has been found in states of decreased or absent consciousness, but also, interestingly, in the unresponsive wakefulness syndrome, indicating that the precuneus is involved in human level conscious awareness, but that its function is dissociable from the systems for arousal and arousal control (Tanabe et al. 2020; Pal et al. 2019; Wu et al. 2019). Studies of attaining lucidity during REM sleep indicate that lucidity is accompanied by increased activation in the precuneus and dIPFC (Dressler et al. 2012; Voss et al. 2014).

As a part of thalamo-cortical networks, the precuneus is extensively connected to thalamus, with different areas of precuneus connecting preferentially but not exclusively to various areas of thalamus. (Cunningham et al. 2017). The precuneus is also connected to the 
brain stem areas of the reticular activating system that supply the necessary arousal (Schiff 2009; Garcia-Rill et al. 2012; Vogt and Laureys 2005). Both of these subcortical areas are necessary but not by themselves sufficient for generating nondual awareness.

Four areas of the precuneus with distinct functional specializations have been identified based on their structural and functional connectivity: dorsal-anterior for somato-motor processing, dorsal-posterior for visual-spatial, ventral posterior for autobiographic self and episodic memory, and the central for cognitive associative processes. (Margulies et al. 2009; Zhang and Li, 2012). Further functional specialization may exist between left and right precuneus (Cavana and Trimble, 2006; Fingelkurts et al. 2020).

The ventral precuneus, together with the posterior cingulate cortex (PCC) and retrosplenial cortex (RSC), is a part of the intrinsic system for processing self-related content, better known as the default mode network (DMN) (Andrew-Hanna et al. 2010). Efforts have been made to differentiate DMN proper, from the parietal episodic memory network proper, which includes caudal portion the ventral precuneus (Zheng et al, 2020). The anterior and posterior dorsal precuneus areas are not parts of the DMN, rather, they are related to the extrinsic system whose spontaneous resting state activity is usually anti-correlated with that of DMN.

Defining the exact anatomical location of the central cognitive precuneus is challenging, as there is a tendency to see any area of the precuneus as belonging either to the intrinsic DMN system, or to the task-positive extrinsic system, and the central precuneus can appear to be a part of one or the other system depending on experimental paradigm (Li et al. 2019). However, it is precisely such functional diversity that defines this area. One of the key functions of the precuneus in general appears to flexibly link DMN with other systems, in particular with the task-positive dorsal and ventral attention (DA, VA) and the fronto-parietal control (FPC) networks (Li et al. 2019; Spreng et al. 2018). While the ventral areas of precuneus link to PCC and DMN, the anterior and posterior dorsal areas link selectively to left or right FPT. It is only the central precuneus that functionally connects with all of the networks, both the intrinsic and the extrinsic (Li et al. 2019). This corresponds to a major function of nondual awareness in increased integration of intrinsic and extrinsic aspects of experience (Josipovic 2012; 2014).

In contrast to this integrative function of the central precuneus network, the salience network which includes the cingulo-opercular areas for the control of arousal, is mainly involved in involuntary switching between the extrinsic and the intrinsic systems, thus contributing under normal conditions to their functional segregation (Menon and Uddin 2010). Nondual awareness is the conscious space in which experience occurs (Rabjam 2001; Josipovic 2019). Not the conceptualized space of distances, routes or boundaries, but the single non-conceptual space encompassing the entire perceptual bubble of any conscious experience, pervading the internal and external environment at the same time. Therefore, it's most likely neural correlates is the central precuneus and its network. 
The oscillatory resonance capacity of neurons is one of the key features enabling their organization into larger assemblies (Lea-Carnall et al. 2016; Buzsaki 2006). The central precuneus network can be modeled as a macro-circuit or a neural net with extensive recurrent connections, which enable it to enter into sustained oscillatory resonance regimes following repeated ignitions (Bazhenov and Timofeev, 2006; Edelman and Tononi 1998; Mashour et al. 2020; Mackey and Heeger, 2019; Moutard et al., 2015).

In respect to nondual awareness, the main purpose of this organization is to enable the network and all its nodes, to inform itself, and by extension the rest of the brain and body, about its own state regarding its availability to process information, which would be experienced as an empty cognizance or awareness that knows itself to be aware, and is, at the same time, open to knowing any information presented to it from the internal and external environment (Josipovic, 2014, 2019). Since this network is informing itself about its ground state at the time, and not about what that state was in the past, or what it may in the future, its dynamic signature will likely be different from that of a recurrent network that is organized to predict its output at some future point given its past state. Such broadcast of the current state in the central precuneus network may correspond to the phenomenal timelessness of nondual awareness.

Of course, a neural network informing itself about its capacity to process information can be instituted in a relatively simple electronic circuit, without any sign of awareness or consciousness, so the biological constraints on a system's capacity for consciousness apply here, and so much more for nondual awareness that requires a human level brain (Baars 2020; Cook et al. 2014; Dehaene et al. 2017; Koch, 2019; Levin 2020).

Oscillatory resonance in neurons may be organized upon the foundation of slow spontaneous fluctuations, such as those seen in the BOLD signal used to define the resting state functional networks in the brain (Raichle 2015). Spontaneous slow fluctuations have been found to correlate with the EEG signals mainly in gamma range (Logothetis et al., 2001), but also in the alpha and very slow wave range, pointing to the cross-frequency organization of EEG oscillations (Buzsaki and Watson, 2012). Interestingly, the pervasive presence of gap-junctions in the cells of many body systems, including the brain, may be involved in enabling a wide range of frequency multiplexing and other dynamics in the bioelectric fields of different networks. (Fukuda 2007; Levin 2020).

It can be hypothesized that during episodes of nondual awareness, the central precuneus macro-circuit would 'rest' in a tonic state of self-sustained oscillatory resonance, in the gamma range, which may exhibit different types of coherence or synchronization characteristics (Balanov et al. 2002; Rausch et al.2018). The prefrontal nodes of this network may then function to add the necessary amplitude and persistence to such network-wide resonance and coherence. (Lou et al. 2020). Additionally, even when its oscillatory resonance stabilizes for longer periods in a low-power mode, as when explicit nondual awareness 
becomes a more or less ongoing presence in one's experience, such a macro-circuit may still need to institute gain control to remain within its optimal range and prevent runaway excitation (Mackey and Heeger, 2019; Miller et al 2014). Recent modeling shows that the activity of thalamo-cortical neurons in alpha range leads to a widespread oscillation suppression, while the tonic activity of thalamocortical cells in gamma range results in entrainment and resonance (Li et al. 2019).

Similar to EEG oscillations in other frequency ranges, the gamma range signal serves different functions in the brain, such as, perceptual, attentional, and, importantly for consciousness, long-range communication (Buzsaki and Watson 2012; Melloni and Singer 2010; Noy et al. 2015; Scheeringa and Fries 2019). The neural mechanisms that generate the observed gamma signals are likewise varied and can be fast feed-forward or local cortical (Noy et al. 2015; Scheeringa and Fries, 2019), or thalamo-cortical (Llinas 2006), but also related to dynamics of travelling waves (Galinski and Frank 2020). A promissing recently proposed method, connectome harmonics, links the $\mathrm{fMRI}$ signal related to global network organization with faster EEG oscillations (Atasoy et al. 2017; Sadaghiani and Wirsich 2020).

Increase in the global fronto-parietal amplitude and phase-synchrony of low gamma band $(25-40 \mathrm{~Hz})$ have been found during nondual or non-referential meditation on compassion (Lutz et al. 2004). Lower prefrontal and higher posterior gamma was found with mindfulness meditation aimed at downregulating DMN (Berkovich-Ohana et al. 2012). An increase in the amplitude of parieto-occipital mid-range gamma $(60-110 \mathrm{~Hz})$ has been found across three different styles of meditation (Braboszcz et al. 2017), while the high-range gamma (100 - 245Hz) correlated with years of meditation experience (Hausweld et al. 2015). Significant increases in current density of gamma band $(35-60 \mathrm{~Hz})$ during progressive stages of nondual awareness meditation were found in ACC, precuneus and superior parietal lobule (Schoenberg et al. 2018). In light of these findings, increased amplitude of EEG signals in low gamma range in parietal and occipital channels found during deep sleep, in long-term meditation practitioners, could be interpreted as the background presence, however faint, of nondual awareness even during NREM sleep without overt lucidity (Ferrarelli et al. 2013). Very high gamma $(>180 \mathrm{~Hz})$ is especially interesting for explicit nondual awareness occurring in meditation, due to its perceived luminosity and subtlety (Lama xiv 2004). Mechanisms that generate these high gamma oscillations will obviously be very different from those generating high gamma signatures of oncoming epileptic seizures (Kobayashi et al. 2017).

\section{Differentiating nondual awareness from functions of consciousness}

Nondual awareness is phenomenally, functionally and, neurally, different from functions of consciousness that are involved in constructing contents, such as voluntary and involuntary attention, tonic and phasic alertness, monitoring, working memory (Dunne 2015; Josipovic, 2019). 
A key function of attention is selection of content. In contrast, nondual awareness is choice-less or non-preferential in relation to content, akin to a mirror's relationship with images reflected in it (Higins 2011). Attending and monitoring imply goal-directed subject-object intentional structures, whereas in nondual awareness such structuring is absent (Josipovic, 2010; Dunne 2015). Meditation methods that rely on attentional mechanisms try to get around this by cultivating bare attention or bare non-distractedness without an object of focus (Dunne 2015). Absorption in such a state may be reported as an experience of nondual awareness without content. However, the observed neural signature of such a state is mainly in the areas of the dorsal attention network, indicating that rather than being a neural signature of pure nondual awareness itself, it most likely reflects the reliance on voluntary focused attention, together with breath retention, to control the contents of one's consciousness (Winter et al. 2020).

Monitoring and vigilance, which are related to tonic and phasic alertness, are the primary functions employed in mindfulness meditation. The neural correlates of such monitoring have been found in areas of the salience network, and the related cingulo-opercular system for arousal control (Lutz et al. 2008; Metzinger 2020; Sadaghiani et al. 2012; Tang et al. 2015). These areas have been proposed as the neural signature of pure awareness encountered in minimal phenomenal experience or absorption (Metzinger, 2020), though, most likely, they reflect monitoring and regulation of alertness rather than being the neural correlate of nondual awareness itself. Interestingly, the central precuneus network for nondual awareness may have a shared node with cingulo-opercular network in dACC (Margulies et al. 2009).

Working memory processing of mental representation relies on the first-order representations in higher perceptual areas, intention in intra-parietal sulcus, conceptual representations and schemas in medial temporal lobe (MTL), and, the online maintenance of representations in dIPFC for the purpose of manipulation (Mashour Dehaene et al., 2020; LeDoux and Lau, 2020; but see Mackey and Curtis 2017, for a different view on dIPFC). Unlike functioning of the working memory during the conceptually based experience, during nondual awareness there is no intentional maintenance and manipulation of representational contents. Thus, while the short-term memory is functioning spontaneously, the working memory is strictly speaking not occupied with anything other than the awareness itself, which is nonconceptual, so the functioning of dIPFC areas involved in nondual awareness will be of a different type then its usual working memory function. (Mackey and Heeger, 2019; Kaminski and Rutishauser, 2020). Likewise, during episodes of nondual awareness, especially if isolated, there will be a decrease in activation and connectivity of the areas of the medial temporal lobe (MTL) that are involved in conceptual representations and schema-based predictions, together with an accompanying decrease in the semantic network areas (Laukkonen and Slagter 2021; Metzinger 2020). 


\section{NRR and other theories of consciousness}

According to the non-representational reflexivity (NRR) theory of consciousness (Josipovic, 2019), the inherent non-representational knowing, that is, awareness that knows itself to be aware in a non-transitive way, is the key property of human consciousness, whether it is only implicit and indirect via mental representations (Peters 2013), or fully explicit and nonrepresentational. Nondual awareness, or consciousness as such, is then the most basic consciousness satisfying this requirement, a ground level of any conscious experience.

Detailed discussion of current theories of consciousness is beyond the scope of this discussion, but briefly outlining a few key points may help clarify the ideas presented here. The main differences between NRR and most other theories of consciousness is that NRR is about consciousness as such, while other theories are about states and contents and what makes them conscious or unconscious. Importantly, from the viewpoint of NRR, current theories conflate consciousness as such with global states and local contents. Additionally, NRR is focused on non-representational consciousness, but it is not an anti-representational theory, as according to it, non-representational and representational processes can co-occur. The NRR is concerned only with one aspect of conscious experience and does not attempt to explain why a state or content is conscious rather than unconscious, but because its properties are reflected in states and contents, it will, in principle, have differentiable effects related to the different zones on its gradient (Josipovic 2019)

The view presented here is similar to the global workspace theories in the sense that a globally distributed system or network is required for explicit nondual awareness (Baars et al. 2013; Mashour et al. 2020), but with one major caveat, that mental representations, such as semantic schema, are not necessary for conscious experience. Rather, consciousness as such, as the most basic awareness, is a non-representational broadcast of the system's current ground state, or in the language of GNW, the broadcast of its own broadcasting capacity (Ricard and Singer, 2017). On this view, when nondual awareness is explicit, the parieto-frontal central precuneus network functions as the core of the global workspace. When it is implicit, the outputs of its various nodes are added as frames to the semantic schema-based broadcast (Josipovic 2019).

Descriptions of phenomenal properties of nondual awareness in NRR have similarity to some of the axioms defining consciousness in the integrated information theory (IIT) (Tononi and Koch, 2015). This is understandable since nondual awareness, whether implicit or explicit, is present in the background of all conscious experiences, and, as discussed above, its properties are reflected in every experience to some extent. However, with the exception of axioms on existence and unity, IIT is largely focused on the problem of content binding, which is in NRR seen as orthogonal to consciousness as such. Occurrence of awareness with very reduced or minimal phenomenal content is problematic for IIT, if the information integration index is regarded as reflecting the amount of phenomenal content. More recently an attempt 
has been made to account for this (Koch, 2019). In respect to the neural correlates, the central precuneus network can be seen to function as an integrated dynamic core with a relatively defined location, which can vary within each node, while the network organization varies between its nodes. It will be interesting to see whether some measure of the implicit-explicit gradient of nondual awareness correlates with the phi measure of integration (Tononi and Koch 2015; Koch 2019)

In respect to the first-order phenomenal theory (Block, 2009) and the related recurrent processing theory (RPT), NRR requires the integrative function of the central precuneus and its network for a content such as perception to be conscious, but to the extent that a perceptual content appears in nondual awareness without subsequent conceptual elaboration, such a perception could be regarded as a true zero-order phenomenal consciousness, since it is free of mental representations and is conscious, and not merely pre-reflective and unconscious (Lamme 2020; Shea and Frith 2016). In that sense, to the extent that nondual awareness can function as the aware space of conceptually constructed experience, it also makes the firstorder representational perception possible as a conscious phenomenal state, once the local perceptual content processing requirement is met (Lamme 2020). The more explicit nondual awareness is, the less constructed perception needs to be. So, in principle, perception could be emptied of all conceptual constructs, associative schema, and of the semantic, iconic or numeric representations, and still be conscious (Fucci et al., 2018; Laukkonen and Slagter 2020). If this is confirmed experimentally, it would invalidate the semantic-schema representational requirements for consciousness, as proposed by the representational theories (Dehaene and Lau 2017).

Although NRR is in essence a non-representational theory, it shares similarities as well as differences with HOT theories. NRR agrees with HOT in that a state or content that is conscious is different from that in virtue of which it is conscious (Rosenthal, 2012), as nondual awareness is different from state and content. However, the neural requirements intrinsic to states and contents have to be met for them to be conscious. On the higher-order theories, the first-order states do not inherit the property of being conscious from higher-order states (Rosenthal, 2012), but according to NRR, as we have seen, the properties of nondual awareness inhere in contents that are present in its space. Even though NRR is so far only concerned with one aspect of conscious experience, namely nondual awareness, the difference between it and HOT can be summed up by saying that, from the perspective of nondual awareness, we are not conscious because we think, we think because we are conscious, and this holds irrespective of how conscious or unconscious the mental representations that make thinking are.

We have discussed the prediction model-based theories (Webb and Graziano 2015; Metzinger 2020) in light of NRR in some detail elsewhere (Josipovic, 2019; Josipovic and Miskovic, 2020), so these will not be covered here. Suffice to say that among these theories, the currently most developed is of pure awareness as the generative predictive model of tonic 
alertness (Metzinger, 2020). NRR sees various internal predictive control models as necessary for optimizing their target functions, but not in themselves as being the neural correlate of nondual awareness, both because of the phenomenal timelessness and choiceless-ness of nondual awareness, and because the neural dynamics proposed by NRR to underly nondual awareness are not fundamentally prediction driven. Even the central evolutionary benefit of prediction models such as managing of free energy and reduction of entropy can be superseded, as the profound and prolonged absorption in this ground state of consciousness can, reportedly, deactivate even the basic biological preference toward preserving one's life (Nikhilananda 1987).

\section{Dimensions of nondual awareness}

When nondual awareness is explicitly present, a number of its properties or dimensions can be self-evident (Higins 2011; Laish, 2015; Metzinger, 2020; Rabjam, 2001; for details see Josipovic, 2019). They can be summarized in a list, as:

1. being or presence - the obvious fact of awareness being present or existing.

2. emptiness - meaning the absence of conceptualizations about itself or phenomena that reify awareness as the subject and the phenomena as objects separate from it; also, unconstructed.

3. nonduality - without subject-object structuring of experience

4 luminosity or radiance - cognitive property appearing as the clear transparent light by which it knows itself and phenomena present to it.

5. non-representational reflexivity - traditionally termed self-knowing or self-recognition (Higins, 2011; Ksemaraja and Singh, 1990; Rabjam, 2001; Laish, 2015; MaKenzie, Williams, 1998), refers to NDA inherently knowing itself to be aware without relying on mediation by mental representations.

6. bliss - silent contentment of being entirely complete in itself, with no sense of any lack or any need

for anything outside of itself, thus without intention.

7. Singularity or unity - nondual awareness is singular and homogenous, a unity of its dimensions, not compounded from them, or from anything else.

8. no self / Self - without a constructed self, but the self-same awareness in all experiences, hence an innermost Self (Siderits et al., 2013; MacKenzie, 2012; Jones, 2021; Josipovic, 2019; Woodhouse, 1978).

9. Boundless spaciousness - single aware space in itself without edges or boundaries that is the background context of any experience, pervading and encompassing both internal and external environment (Ansel, ...; Rabjam and Barron, 2001).

Although in principle all dimensions are equally one within nondual awareness' singularity, different dimensions can appear more or less prominent in one's experience due to a number of individual and situational factors (Josipovic 2019). Because nondual awareness 
when explicit functions as the aware space of experience, any conscious state and content present with it at that time will to some extent reflect its properties, as their neural correlates are recruited or linked with the current state of the central precuneus network (Josipovic 2014).

It can now be seen how nondual awareness can be modeled as a multi-dimensional state space where each of its properties is a dimension. Each property can be represented by a vector specifying its vividness, clarity, persistence, etc. (Metzinger, 2020). The z-axis added to the standard 2D map of consciousness and representing the implicit-explicit gradient of nondual awareness, would then be a summation vector of the vectors for all its properties.

\section{The implicit-explicit gradient}

The gradient of nondual awareness informs about how nondual awareness appears in experience independent from the global state and local content properties of that experience. This gradient can be thought of as having three main zones or clusters: implicit, transitional and explicit. Like many other features of human experience, these are both continuous and discrete.

When nondual awareness is implicit, it is obscured from itself and replaced by mental representations that construct conceptually reified subject and object and create the dualistic fragmenting of experience (Germano and Waldron 2006; Higins 2011; Metzinger 2020; Thompson 2020).

Direct non-representational knowing becomes obscured by the representation-based transitive thinking. The property of being-presence becomes obscured by the reified notion of existence and by grasping for it. The property of emptiness becomes obscured by the reified notion of nonexistence, and by the fear of it. The property of bliss of being complete in itself, becomes obscured by craving and reward seeking (Rabjam 2007).

This organization of experience has been termed duality (Josipovic 2014). It fragments experience into opposing poles, such as mind vs. body, inside vs. outside, self vs. other, us vs. them, etc., which cause pervasive unnecessary discontent and suffering (Josipovic 2016). On this view, the more implicit nondual awareness is, the more dualistic and fragmented the experience is, or in the language of prediction theories, the more it becomes covered up by the self-world model and its predictions (Josipovic 2016; Metzinger 2020; Laukkonen and Slagter 2020). A range of duality can be found both within healthy experience, and within clinical conditions. When an experience is one of comfort and ease, there will be less dualistic fragmentation and the properties of nondual awareness, though still known only indirectly, will be more apparently reflected in experience. For example, being-presence will be reflected as peacefulness, awareness as an abatement of fixated beliefs, bliss as enjoyment and happiness, and singularity as authenticity and connectedness. When an experience is one of ongoing stress and struggle, or when the survival mechanisms and ego-defenses are chronically overactive 
(Kernberg 1984; Kohut 2009; LeDoux, Peter Levine), the dualistic fragmentation will be more pronounced, and the nondual awareness and its qualities will usually be more obscured.

The transitional zone of the gradient has two sections. The first one, related to a variety of unitary experiences that reflect to some extent the properties of nondual awareness, but without nondual awareness directly recognizing itself. And the second one, in which nondual awareness recognizes itself directly as that which is aware, and this self-recognition - the activation of its non-representational reflexivity, transitions from being a rare flash of insight, to being a more or less permanent presence.

Unitary experiences are possible because nondual awareness is present in the background of all experiences, even when unrecognized. When the endogenous or exogenous conditions cause the dualistic subject-object self-world model to temporarily relax or cease, commonly reported as ego dissolution (Nour et al. 2016; Yaden et al. 2017), properties of nondual awareness become more clearly reflected in experiences, giving them, among other properties, their unitary character.

The extent to which any property of nondual awareness is reflected in an experience depends on the specifics of its global state and local content. In terms of their global state, unitary experiences could be grouped into those with low levels of arousal such as found in deep relaxation and in deep sleep-like meditative absorption, those with medium levels of arousal as in various experiences of unity during normal waking, and those occurring with higher levels of arousal as in various altered states (Barrett and Griffits 2018; Josipovic 2019; Metzinger 2020; Srinivasan 2020). Likewise, in terms of the amount of content they can be grouped into those with low amount such as occurring due to sustained focused attention on a single object or in absorption without an object, medium waking-level amount of content, or those with high amount of content as found in some psychedelic experiences and in complex meditations like deity yoga. Since states and contents interact, there will an overlap, such that for example vividness may characterize content but also be related to alertness and the level of arousal. (Fazekas et al. 2020).

Even more important may be the type of content, whether it is predominantly perceptual, affective or cognitive. Thus, an experience in which somatosensory interoceptive content predominates may reflect the property of being-presence more strongly; an experience of ecstatic love may reflect the property of bliss most strongly, an experience of meditational mental image may reflect the property of luminosity most strongly, while an experience of mental quiescence and absorption may reflect emptiness most strongly. Of course, all of the properties of nondual awareness are unified in its singular presence, so, all will be reflected in every phenomenal content to some extent, though some more than others (Josipovic 2019).

A related feature of content is how concrete or subtle it is. The more subtle the content, the more clearly it can reflect the properties of nondual awareness. For example, a more subtle 
experience of internal and external energy can reflect the unity property more strongly than the coarser experience of materiality of the body and objects in the environment. Further along in subtlety, an actual - not merely imaginary - formless experience, such as that of infinite light, can reflect the properties of nondual awareness intensely and with relatively little distortion.

However, while subjects may report awareness as part of their unitary experiences, the common characteristic of all experiences in this group is that they don't yet include the direct self-recognition of nondual awareness by itself (Hanley et al. 2015).

The second section of the transitional zone of the gradient is related to the initial awakening of nondual awareness to itself. This is the key aspect of the gradient, the awakening of the self-knowing property of awareness, its non-representational reflexivity, since without it activating, nondual awareness is not truly known nor realized, and neither it nor its dimensions can stabilize.

Two parallel processes usually need to occur for the self-recognition to ignite: 1. the conceptual processes that construct the reified subject and objects need to temporarily stop, for awareness to emerge from behind them and be present however briefly, relatively unobscured, but long enough to disidentify or unglue itself from the constructed self. 2. nondual awareness needs to so to speak wake up to itself. Its direct non-representational reflexivity needs to activate, so that it can see directly "its own face". It needs to become aware of itself directly, without conceptualizations about itself (Ksemaraja and Singh 1990; Rabjam 2007).

However, other than these two, nothing else needs to happen. Once there is a sufficient abatement of self-specifying mental representations, nondual awareness can recognize itself in any experience irrespective of the degree of alertness or arousal and irrespective of the amount or type of the content (. This is frequently not understood, and the shutting down of perceptual, affective and cognitive content is confused with nondual awareness (Josipovic and Miskovic 2020; Srinivasan 2020) But the resultant states of mental quiescence, and even bare non-conceptuality, are not in and of themselves nondual awareness (Thompson, 2020).

What actually causes the ignition of self-knowing is not known, other than it is a spontaneously occurring event, and that some strategies, like attending to awareness as in awareness-of-awareness practices, or questioning as in self-inquiry practices, can facilitate it.

Interestingly, the relation between two processes is asymmetric. While the ignition of this intuitive leap is sine-qua-non of self-recognition, the abatement of self-specifying mental representations and even of dualistic subject-object structuring, is not. Paradoxically, nondual awareness' knowing of itself can ignite even with the presence of dualistic subject-object conceptualizations. Or, as meditation adept Saraha stated:

"...the radiance of self-awareness in awareness and un-awareness...

...shines without removing the grime of subject and object." (Saraha, as quoted in Higins 2008) 
The explicit zone of the gradient is characterized by the progressive stabilizing of nondual awareness and its coming into the foreground of experience (Rangdrol 1990). It has three sections.

The first one, of realizing the identity of nondual awareness and space, in which nondual awareness becomes established as the ongoing space-like context, and all states and contents irrespective of how they are constructed, are experienced within it, as within a metaphoric ground of being (Blackstone 2007).

At first only perceptions can be included within its space, but gradually as it becomes progressively more stable, the affective and cognitive aspect of experience can also be brought within its space. Finally, when this is stable it can include even the dualistic representational constructs specifying subject-object (Rabjam 2001).

The second one, in which nondual awareness is experienced within all contents and states, as that which they are made of, and all its properties are reflected clearly in experiences. Here nondual awareness appears as both the aware space in which conscious states and contents occur, and as the substance out of which they are made, so it is experienced as simultaneously transcendent and immanent in experience (Josipovic 2016; 2019).

And the third section is that of full unity, in which both the ground and all contents and states within it, are single in being who one is, a spontaneously occurring authentic presence (Klein and Wangyal 2006)

As discussed above, perhaps the most challenging issue for determining the neural correlates of nondual awareness is that nondual awareness can, in principle, co-occur with almost any conscious content or state, so that, when a specific change in the state or content is used to get to it, the neural signature of nondual awareness can be obscured by the neural signatures of that change (Josipovic and Miskovic 2020). Recent advances in connectomics, deep neural nets and modeling of the brain dynamics, have bought a plethora of indexes of integration. It remains to be seen to what extent they reflect the actual neural mechanisms in the brain (Hahn et al. 2021).

Be that as it may, it can be surmised that the more dualistic and fragmented an experience is, the less optimally integrated the global brain organization will be. This is most evident in clinical cases which show signatures of global disorganization, such as higher entropy and decreased functional segregation between resting states networks accompanied by the loss of their internal coherence (Sheffield and Barch 2016). On the other end of the disorder spectrum, global disorganization can be due to a hyper-synchronization, as in epileptic disorder (Kobayashi et al. 2017). Healthy conscious dualistic experiences, when nondual awareness is implicit, show the opposite signatures, a reduced entropy and more enduring attractor organization (Carhart-Harris 2018). 
The duality will be reflected in more distinct attractors such as front-back, left-right, etc., or more rigid functional segregation of the resting state networks. Given that the implicit zone of the gradient is characterized by nondual awareness not knowing itself directly, this should be accompanied by a decrease in sustained oscillatory resonance and intra-network functional and effective connectivity in the central precuneus network. When implicit, nondual awareness is covered up by the conceptually reified self and the self-related activity of DMN and MTL (Josipovic et al. 2012).

In respect to the transitional zone of the gradient, the neural correlates of the activation of non-representational reflexivity will be related to the ignition in the central-precuneus network, and its more permanent presence in one's experience, to establishing of a more sustained oscillatory resonance and coherence or synchrony, as previously proposed (Josipovic, 2019). When nondual awareness is isolated from content, this signature may be more restricted to the areas of the central-precuneus network alone. During instances of fully isolated or pure nondual awareness, when other phenomenal contents are minimized, the overall activity of the precuneus may gravitate toward the central precuneus itself, away from both the ventral portion related to self and episodic memory, and the dorsal areas for visuo-motor processing. Likewise, during those times, a corresponding shift may be postulated for the lateral prefrontal cortex (Josipovic, 2019).

The neural correlates of explicit nondual awareness will be seen in the effects of the central precuneus network on the global organization of the brain, in the measures of increased functional integration and oscillatory coherence or synchronization (Josipovic 2014, 2019; Lutz et al. 2004). Akin to psychedelic states, explicit nondual awareness will exhibit global dynamic signatures of criticality, poised between too much disorganization and too much organization (Barrett and Griffits 2018; Carhart-Harris 2018; Milliere et al. 2018; ). In terms of DMN, when nondual awareness is explicit, and especially during a waking state, the medial parietal activity will shift dorsally toward the central precuneus network(Josipovic 2014). Perception in nondual awareness shows less top-down prediction, corresponding to subjects reporting less concepts and associative memory tagging onto perceptions (Fucci et al., 2018; Laukkonen and Slaggter 2020). Relaxation of different layers of conceptually constructed self, a common effect of many contemplative methods (Dor-Ziderman et al. 2016; Dahl et al. 2015), occurs with nondual awareness as well, though attenuation of DMN may be less pronounced than in FA or OM style meditations, as NDA can embrace any type of content. On the level of body-based self, the relaxation of the reified representations of body boundary may be seen in decreased connectivity between the central precuneus and r-TPJ/ANG (Josipovic, 2014; Laukonnen and Slagter, 2020; Metzinger, 2020). 


\section{Conclusion}

Extracting awareness out of contents and states and mapping it onto the z-axis as the gradient of how implicit or explicit it appears in experience, can now be seen to add clarity to attempts to systematize unitary or mystical experiences. Their various characteristics, which have been thought to give them their uniqueness such as ego-dissolution or introvert-extrovert features, can now be dissociated from the specifics of their states and contents, and seen as related to the properties of nondual awareness as specified by its gradient. 


\section{REFERENCES}

Amihai, I., and Kozhevnikov, M. (2014). Arousal vs. relaxation: a comparison of the neurophysiological and cognitive correlates of Vajrayana and Theravada meditative practices. PLoS One 9:e102990. doi: 10.1371/journal.pone.0102990

Andrews-Hanna, J.R., Reidler, J.S., Sepulcre, J., et al. 2010. Functional-anatomic fractionation of the brain's default network. Neuron. 65, 550-562.

Anspal S. Lost in space: Tibetan formulations of rDzog-chen long-de. Acta Orientalia 2005 66:173-193.

Aru J, Suzuki M, Rutiku R, Larkum ME and Bachmann T (2019) Coupling the State and Contents of Consciousness. Front. Syst. Neurosci. 13:43. doi: 10.3389/fnsys.2019.00043

Ataria Y, Dor-Ziderman Y, Berkovich-Ohana A. How does it feel to lack a sense of boundaries? A case study of a long-term mindfulness meditator. Conscious Cogn. 2015 Dec;37:133-47. doi:

10.1016/j.concog.2015.09.002.

Atasoy S, Deco G, Kringelbach ML, Pearson J. Harmonic Brain Modes: A Unifying Framework for Linking Space and Time in Brain Dynamics. Neuroscientist. 2018 Jun;24(3):277-293. doi: $10.1177 / 1073858417728032$.

Baars BJ. The Hard Problem is Mainly Hard Work. Cogn Neurosci. 2020 Nov 26:1-2. doi: 10.1080/17588928.2020.1838474

Baars, B.J., 2013. A scientific approach to silent consciousness. Frontiers in Psychology, 4, 1-3. Baars, B.J., Franklin, S., Ramsoy, T.Z., 2013. Global workspace dynamics: Cortical binding and propagation enables conscious contents. Frontiers in Psychology, 4, 1-22.

Bachmann T. How to Begin to Overcome the Ambiguity Present in Differentiation between Contents and Levels of Consciousness? Front Psychol. 2012 Mar 21;3:82. doi: 10.3389/fpsyg.2012.00082.

Balanov AG, Janson NB, Postnov DE, McClintock PV. Coherence resonance versus synchronization in a periodically forced self-sustained system. Phys Rev E Stat Nonlin Soft Matter Phys. 2002 Apr;65(4 Pt 1):041105. doi: 10.1103/PhysRevE.65.041105.

Barrett FS, Griffiths RR. Classic Hallucinogens and Mystical Experiences: Phenomenology and Neural Correlates. Curr Top Behav Neurosci. 2018;36:393-430. doi: 10.1007/7854_2017_474.

Bayne T, Carter O. Dimensions of consciousness and the psychedelic state. Neurosci Conscious. 2018 Sep 19;2018(1):niy008. doi: 10.1093/nc/niy008.

Bayne, T., Hohwy, J., and Owen, A. M. (2016). Are there levels of consciousness?

Trends Cogn. Sci. 20, 405-413. doi: 10.1016/j.tics.2016.03.009

Bazhenov M. and Timofeev I. Thalamocortical Oscillations. Scholarpedia, 2006; 1(6):1319. doi:10.4249/scholarpedia.1319 
Berkovich-Ohana A, Glicksohn J. The consciousness state space (CSS)-a unifying model for consciousness and self. Front Psychol. 2014 Apr 29;5:341. doi: 10.3389/fpsyg.2014.00341.

Berkovich-Ohana A, Glicksohn J, Goldstein A. Mindfulness-induced changes in gamma band activity implications for the default mode network, self-reference and attention. Clin Neurophysiol. 2012 Apr;123(4):700-10. doi: 10.1016/j.clinph.2011.07.048.

Blackstone J. (2007) The Empathic Ground: Intersubjectivity and Nonduality in the Psychotherapeutic Process. Albany: SUNY Press.

Block, N., 2007. Consciousness, accessibility and the mesh between psychology and between psychology and neuroscience. Behav. Brain Sci. 30, 481-548.

Boly, M.M., Massimini, M., Garrido, I., et al. 2012. Brain connectivity in disorders of consciousness. Brain Connect. 2, 1-10.

Braboszcz C, Cahn BR, Levy J, Fernandez M, Delorme A. Increased Gamma Brainwave Amplitude Compared to Control in Three Different Meditation Traditions. PLoS One. 2017 Jan 24;12(1):e0170647. doi: 10.1371/journal.pone.0170647.

Brown R, Lau H, LeDoux JE. Understanding the Higher-Order Approach to Consciousness. Trends Cogn Sci. 2019 Sep;23(9):754-768. doi: 10.1016/j.tics.2019.06.009.

Buckner RL, DiNicola LM. The brain's default network: updated anatomy, physiology and evolving insights. Nat Rev Neurosci. 2019 Oct;20(10):593-608. doi: 10.1038/s41583-019-0212-7.

Buzsaki, G., 2006. Rhythms of the brain. New York: Oxford University Press.

Buzsaki, G., Wang, X.J., 2012. Mechanisms of Gamma Oscillations. Annu. Rev. Neurosci. 35, 203-225.

Carhart-Harris RL. The entropic brain-Revisited. Neuropharmacology 2018; doi:

10.1016/j.neuropharm.2018.03.010.

Carhart-Harris, R. L., Erritzoe, D., Haijen, E., Kaelen, M., and Watts, R. (2018). Psychedelics and connectedness. Psychopharmacology 235, 547-550. doi: 10. 1007/s00213-017-4701-y

Cavanna, A.E., Trimble, M.R., 2006. The precuneus: a review of its functional anatomy and behavioural correlates, Brain, 129, 3, 564-583.

Cook, N.D., Carvalho, G.B., Damasio, A., 2014. From membrane excitability to metazoan psychology. Trends in Neurosciences, 37, 12, 698-705.

Cunningham SI, Tomasi D, Volkow ND. Structural and functional connectivity of the precuneus and thalamus to the default mode network. Hum Brain Mapp. 2017 Feb;38(2):938-956. doi:

10.1002/hbm. 23429

Dahl, C.J., Davidson, R.J., Lutz, A., 2015. Reconstructing and deconstructing the self: cognitive mechanisms in meditation practice. Trends Cogn. Sci. 19, 515-523. 
Dainton B. The gaze of consciousness. Journal of Consciousness Studies, 9, No. 2, 2002, pp. 31-48.

Dehaene S, Lau H, Kouider S. What is consciousness, and could machines have it? Science. 2017 Oct 27;358(6362):486-492. doi: 10.1126/science.aan8871.

Dor-Ziderman, Y., Ataria, Y., Fulder, S., Goldstein, A., and Berkovich-Ohana, A. (2016). Self-specific processing in the meditating brain: a MEG neurophenomenology study. Neurosci. Conscious. 2016:niw019. doi: 10.1093/nc/niw019

Dressler, M.R., Wehrle, R., Spoormaker, V.I., et al. 2012. Neural correlates of dream lucidity obtained from contrasting lucid versus non-lucid REM sleep: a combined EEG/fMRI case study. Sleep, 7, 10171020.

Dunne, J. D. (2015). "Buddhist styles of mindfulness: a heuristic approach" in Handbook of mindfulness and self-regulation. eds. B. D. Ostafm, M. D. Robinson and B. P. Meier (New York: Springer), 251270.

Dunne JD, Thompson E, Schooler J. Mindful meta-awareness: sustained and non-propositional. Curr Opin Psychol. 2019 Aug;28:307-311. doi: 10.1016/j.copsyc.2019.07.003

Edelman, G.M., Tononi, G., 1998. Science, 282, 1846-51.

Fasching W. Prakāśa. A few reflections on the Advaitic understanding of consciousness as presence and its relevance for philosophy of mind. Phenomenology and the Cognitive Sciences 2020 doi.org/10.1007/s11097-020-09690-2

Fazekas P, Nemeth G, Overgaard M. Perceptual Representations and the Vividness of Stimulus-Triggered and Stimulus-Independent Experiences. Perspect Psychol Sci. 2020 Sep;15(5):1200-1213. doi: $10.1177 / 1745691620924039$.

Fazekas P, Overgaard M. Multidimensional Models of Degrees and Levels of Consciousness. Trends Cogn Sci. 2016 Oct;20(10):715-716. doi: 10.1016/j.tics.2016.06.011.

Ferrarelli, F., Smith, R., Dentico, D., et al. 2013. Experienced mind fulness meditators exhibit higher parietal-occipital EEG gamma activity during NREM sleep. PLoS ONE, 8, 8, e73417.

Fingelkurts AA, Fingelkurts AA, Kallio-Tamminen T. Selfhood triumvirate: From phenomenology to brain activity and back again. Conscious Cogn. 2020 Nov;86:103031. doi: 10.1016/j.concog.2020.103031

Forman, R. K. C. (1998). What does mysticism have to teach us about consciousness? J. Conscious. Stud. 5, 185-201.

Fucci E, Abdoun O, Caclin A, Francis A, Dunne JD, Ricard M, Davidson RJ, Lutz A. Differential effects of non-dual and focused attention meditations on the formation of automatic perceptual habits in expert practitioners. Neuropsychologia. 2018 Oct;119:92-100. doi: 10.1016/j.neuropsychologia.

Fukuda T. Structural organization of the gap junction network in the cerebral cortex. Neuroscientist. 2007 Jun;13(3):199-207. doi: 10.1177/1073858406296760. 
Galinsky VL and Frank LR Brain Waves: Emergence of Localized, Persistent, Weakly Evanescent Cortical Loops. J Cogn Neurosci 2020 Nov;32(11):2178-2202. doi: 10.1162/jocn_a_01611.

Gallese, V. Embodied simulation: From neurons to phenomenal experience. Phenom Cogn Sci 4, 23-48 (2005). https://doi.org/10.1007/s11097-005-4737-z

Garcia-Rill, E., Kezunovic, N., Hyde, J., et al. 2012. Coherence and frequency in the reticular activating system (RAS). Sleep Med Rev. 17, 3, 227-238.

Germano, D.F., Waldron, W.S., 2006. A comparison of alaya-vijnana in Yogachara and Dzogchen. in: Nauriyal, D.K., Drummond, M.S., Lal, Y.B., (Eds.), Buddhist thought and applied psychology research. Routledge, New York, pp. 36-68.

Grund M, Forschack N, Nierhaus T, Villringer A. Neural correlates of conscious tactile perception: An analysis of BOLD activation patterns and graph metrics. Neuroimage. 2021 Jan 1;224:117384. doi: 10.1016/j.neuroimage.2020.117384.

Hahn G, Zamora-López G, Uhrig L, Tagliazucchi E, Laufs H, Mantini D, Kringelbach ML, Jarraya B, Deco G. Signature of consciousness in brain-wide synchronization patterns of monkey and human fMRI signals. Neuroimage. 2021 Feb 1;226:117470. doi: 10.1016/j.neuroimage.2020.117470.

Hanley AW, Nakamura Y, Garland EL. The Nondual Awareness Dimensional Assessment (NADA): New tools to assess nondual traits and states of consciousness occurring within and beyond the context of meditation. Psychol Assess. 2018 Dec;30(12):1625-1639. doi: 10.1037/pas0000615.

Hanoğlu L, Özkara Ç, Yalçiner B, Nani A, Cavanna AE. Epileptic qualia and self-awareness: a third dimension for consciousness. Epilepsy Behav. 2014 Jan;30:62-5. doi: 10.1016/j.yebeh.2013.09.010.

Hauswald A, Übelacker T, Leske S, Weisz N. What it means to be Zen: marked modulations of local and interareal synchronization during open monitoring meditation. Neuroimage. 2015 Mar;108:265-73. doi: 10.1016/j.neuroimage.2014.12.065.

Heeger DJ, Mackey WE. Oscillatory recurrent gated neural integrator circuits (ORGaNICs), a unifying theoretical framework for neural dynamics. Proc Natl Acad Sci U S A. 2019 Nov 5;116(45):22783-22794. doi: 10.1073/pnas.1911633116.

Helfrich RF, Knight RT. Oscillatory Dynamics of Prefrontal Cognitive Control. Trends Cogn Sci. 2016 Dec;20(12):916-930. doi: 10.1016/j.tics.2016.09.007.

Higins 2008. On the development of non-mentation doctrine in Indo-Tibetan Buddhism. Journal of the International Association of Buddhist Studies Volume $29 \bullet$ Number 2 • 2006 (2008) pp. 255-303

Higins, D. (2011). A reply to questions concerning mind and primordial knowing - an annotated translation and critical edition of Klongchen pa's Sems dang ye shes kyi dris lan. J. Int. Assoc. Buddh. Stud. 34, 31-96. 
Hunt T, Schooler JW. The Easy Part of the Hard Problem: A Resonance Theory of Consciousness. Front Hum Neurosci. 2019 Oct 31;13:378. doi: 10.3389/fnhum.2019.00378

Josipovic, Z. (2010). Duality and nonduality in meditation research. Conscious. Cogn. 19, 1119-1121. doi: 10.1016/j.concog.2010.03.016

Josipovic, Z. (2014). Neural correlates of nondual awareness in meditation. Ann. N. Y. Acad. Sci. 1307, 9-18. doi: 10.1111/nyas.12261

Josipovic, Z. (2016). Love and compassion meditation: a nondual perspective. Ann. N. Y. Acad. Sci. 1373, 65-71. doi: 10.1111/nyas.13078

Josipovic, Z. (2019). Nondual awareness: consciousness-as-such as non- representational reflexivity. Prog. Brain Res. 244, 273-298. doi: 10.1016/ bs.pbr.2018.10.021

Josipovic, Z., and Baars, B. J. (2015). Editorial: what can neuroscience learn from contemplative practices? Front. Psychol. 6:1731. doi: 10.3389/fpsyg.2015.01731

Josipovic, Z., Dinstein, I., Weber, J., and Heeger, D. J. (2012). Influence of meditation on anticorrelated networks in the brain. Front. Hum. Neurosci. 5:183. doi: 10.3389/fn-hum.2011.00183

Josipovic Z. and Miskovic V. Nondual awareness and minimal phenomenal experience. Front. in Psych 2020; doi: 10.3389/fpsyg.2020.02087

Kamiński J, Rutishauser U. Between persistently active and activity-silent frameworks: novel vistas on the cellular basis of working memory. Ann N Y Acad Sci. 2020 Mar;1464(1):64-75. doi:

$10.1111 /$ nyas.14213.

Kernberg OF. 1984 Severe Personality Disorders: Psychotherapeutic Strategies. Yale University Press.

Klein AC. and Wangyal TR 2006. Unbounded Wholeness: Dzogchen, Bon, and the Logic of the Nonconceptual. Oxford University Press.

Kobayashi K, Akiyama T, Agari T, Sasaki T, Shibata T, Hanaoka Y, Akiyama M, Endoh F, Oka M, Date I. Significance of High-frequency Electrical Brain Activity. Acta Med Okayama. 2017 Jun;71(3):191-200. doi: 10.18926/AMO/55201.

Koch, C. (2019). The feeling of life itself: Why consciousness is widespread but can't be computed. Cambridge: MIT Press.

Koch C, Massimini M, Boly M, Tononi G. Neural correlates of consciousness: progress and problems. Nat Rev Neurosci 2016;17: 307-21.

Kohut H. 2009 The Restoration of Self. Chicago University Press.

Krageloh C. Phenomenological Research Fails to Capture the Experience of Nondual Awareness. Mindfulness 2018 doi.org/10.1007/s12671-018-0995-z 
Ksemaraja, and Singh, J. (1990). The doctrine of recognition. Albany, NY: SUNY Press.

Laish E.(2015).Natura awareness: the discovery of authentic being in the rDzogs-chen tradition. Asian. Philos. 25, 34-64. doi: 10.1080/09552367.2015.1016735

Lama, D. xiv., 2004. Dzogchen. Ithaca: Snow Lion.

Lamme, V., 2015. The Crack of Dawn. Open MIND 22. https://doi.org/10.15502/978395857009 Lamme VAF. Visual Functions Generating Conscious Seeing. Front Psychol. 2020 Feb 14;11:83. doi: 10.3389/fpsyg.2020.00083.

Laukkonen R, and Slagter H. (2020). From many to one: Meditation and the plasticity of the predictive mind. doi: 10.31234/osf.io/5sw6m

Laureys S. The neural correlate of (un)awareness: lessons from the vegetative state. Trends Cogn Sci 2005;9:556-9.

Lea-Carnall CA, Montemurro MA, Trujillo-Barreto NJ, Parkes LM, El-Deredy W. Cortical Resonance Frequencies Emerge from Network Size and Connectivity. PLoS Comput Biol. 2016 Feb 25;12(2):e1004740. doi: 10.1371/journal.pcbi.1004740.

LeDoux JE, Lau H. Seeing consciousness through the lens of memory. Curr Biol. 2020 Sep 21;30(18):R1018-R1022. doi: 10.1016/j.cub.2020.08.008.

Levin M. Life, death, and self: Fundamental questions of primitive cognition viewed through the lens of body plasticity and synthetic organisms. Biochem Biophys Res Commun. 2020 Nov 5:S0006291X(20)32006-4. doi: 10.1016/j.bbrc.2020.10.077.

Li G, Henriquez CS, Fröhlich F. Rhythmic modulation of thalamic oscillations depends on intrinsic cellular dynamics. J Neural Eng. 2019 Feb;16(1):016013. doi: 10.1088/1741-2552/aaeb03.

Li R, Utevsky AV, Huettel SA, Braams BR, Peters S, Crone EA, van Duijvenvoorde ACK. Developmental Maturation of the Precuneus as a Functional Core of the Default Mode Network. J Cogn Neurosci. 2019 Oct;31(10):1506-1519. doi: 10.1162/jocn_a_01426.

Llinas, R.R., 2006. Bursting of Thalamic Neurons and States of Vigilance. Journal of Neurophysiology, 95, 6, 3297-3308.

Logothetis NK, Pauls J, Augath M, Trinath T, Oeltermann A. Neurophysiological investigation of the basis of the fMRI signal. Nature. 2001 Jul 12;412(6843):150-7. doi: 10.1038/35084005.

Lou HC, Rømer Thomsen K, Changeux JP. The Molecular Organization of Self-awareness: Paralimbic Dopamine-GABA Interaction. Front Syst Neurosci. 2020 Jan 28;14:3. doi: 10.3389/fnsys.2020.00003.

Lutz,A.,Greischar,L.L.,Rawlings, N. B.,Ricard,M., and Davidson, R. J.(2004). Long-term meditators self-induce high-amplitude gamma synchrony during mental practice. Proc.Natl.Acad.Sci.U.S.A. 101, 16369-16373. 
Lutz, A., and Thompson, E. (2003). Neurophenomenology: integrating subjective experience and brain dynamics in the neuroscience of consciousness. J. Conscious. Stud. 10, 31-52.

Lutz, A., Slagter, H. A., Dunne, J. D., and Davidson, R. J. (2008). Attention regulation and monitoring in meditation. Trends Cogn. Sci. 12, 163-169. doi: 10.1016/j.tics.2008.01.005

MacKenzie M. (2015): Reflexivity, Subjectivity, and the Constructed Self: A Buddhist Model, Asian Philosophy, DOI: 10.1080/09552367.2015.1078140

Mackey WE, Curtis CE. Distinct contributions by frontal and parietal cortices support working memory. Sci Rep. 2017 Jul 21;7(1):6188. doi: 10.1038/s41598-017-06293-x.

Manjusrimitra, and Lipman, K. (2001). Primordial experience. Boston: Shambhala.

Margulies, D.S., Vincent, J.L., Kelly, C., et al. 2009. Precuneus shares intrinsic functional architecture in humans and monkeys. Proceedings of the National Academy of Sciences of the United States of America, 106, 47, 20069-20074.

Martial C, Larroque SK, Cavaliere C, Wannez S, Annen J, Kupers R, Laureys S, Di Perri C. Resting-state functional connectivity and cortical thickness characterization of a patient with Charles Bonnet syndrome. PLoS One. 2019 Jul 18;14(7):e0219656. doi: 10.1371/journal.pone.0219656.

Martial C, Simon J, Puttaert N, Gosseries O, Charland-Verville V, Nyssen AS, Greyson B, Laureys S, Cassol $\mathrm{H}$. The Near-Death Experience Content (NDE-C) scale: Development and psychometric validation. Conscious Cogn. 2020 Nov;86:103049. doi: 10.1016/j.concog.2020.103049.

Mashal N, Vishne T, Laor $\mathrm{N}$. The role of the precuneus in metaphor comprehension: evidence from an fMRI study in people with schizophrenia and healthy participants. Front Hum Neurosci. 2014 Oct 16;8:818. doi: 10.3389/fnhum.2014.00818.

Mashour GA, Hudetz AG. Neural Correlates of Unconsciousness in Large-Scale Brain Networks. Trends Neurosci. 2018 Mar;41(3):150-160. doi: 10.1016/j.tins.2018.01.003.

Mashour GA, Roelfsema P, Changeux JP, Dehaene S. Conscious Processing and the Global Neuronal Workspace Hypothesis. Neuron. 2020 Mar 4;105(5):776-798. doi: 10.1016/j.neuron.2020.01.026.

Melloni, L., Singer, W., 2010. Distinct characteristics of conscious experience are met by large-scale neuronal synchronization. in: Perry, E.K, Collerton, D., LeBeau, F.E.N., Ashton, H., (Eds.), New horizons in the neuroscience of consciousness. John Benjamins, Amsterdam, pp. 17-28.

Menon, V., Uddin, L.Q. Saliency, switching, attention and control: a network model of insula function. Brain Struct Funct 214, 655-667 (2010). https://doi-org.proxy.library.nyu.edu/10.1007/s00429-0100262-0

Metzinger, T. (2020). Minimal phenomenal experience: meditation, tonic alertness, and the phenomenology of "pure" consciousness. Philos. Mind Sci. 1, 1-44. doi: 10.33735/phimisci.2020.I.46 
Miller, J. E., Ayzenshtat, I., Carrillo-Reid, L., and Yuste, R. (2014). Visual stimuli recruit intrinsically generated cortical ensembles. Proc. Natl. Acad. Sci. U.S.A. 111, E4053-E4061. doi:

10.1073/pnas.1406077111

Milliere, R., Carhart-Harris, R. L., Roseman, L., Trautwein, F. -M., and Berkovich-Ohana, A. (2018). Psychedelics, meditation and self-consciousness. Front. Psychol. 9:1475. doi:

10.3389/fpsyg.2018.01475

Moutard C, Dehaene S, Malach R. Spontaneous Fluctuations and Non-linear Ignitions: Two Dynamic Faces of Cortical Recurrent Loops. Neuron. 2015 Oct 7;88(1):194-206. doi:

10.1016/j.neuron.2015.09.018.

Nikhilananda, S., 1987. Atmabodha of Shankaracharya. Madras: Sri Ramakrishna Math.

Nour MM, Evans L, Nutt D and Carhart-Harris RL (2016) Ego-Dissolution and Psychedelics: Validation of the Ego-Dissolution Inventory (EDI). Front. Hum. Neurosci. 10:269. doi: 10.3389/fnhum.2016.00269

Noy N, Bickel S, Zion-Golumbic E, Harel M, Golan T, Davidesco I, Schevon CA, McKhann GM, Goodman RR, Schroeder CE, Mehta AD, Malach R. Ignition's glow: Ultra-fast spread of global cortical activity accompanying local "ignitions" in visual cortex during conscious visual perception. Conscious Cogn. 2015 Sep;35:206-24. doi: 10.1016/j.concog.2015.03.006.

Pal D, Li D, Dean JG, Brito MA, Liu T, Fryzel AM, Hudetz AG, Mashour GA. Level of Consciousness Is Dissociable from Electroencephalographic Measures of Cortical Connectivity, Slow Oscillations, and Complexity. J Neurosci. 2020 Jan 15;40(3):605-618. doi: 10.1523/JNEUROSCI.1910-19.2019.

Pereira-Pedro, S.A., Bruner, E., 2016. Sulcal pattern, extension, and morphology of the precuneus in adult humans. Annals of Anatomy, 208, 85-93.

Peters, F., 2013. Theories of consciousness as reflexivity. Philosophical Forum, 44, 4, 341-372.

Petitmengin, C., van Beek, M., Bitbol, M., Nissou, J. M., and Roepstorff, A. (2019). Studying the experience of meditation through Micro-phenomenology. Curr. Opin. Psychol. 28, 54-59. doi: 10.1016/j.copsyc.2018.10.009

Rabjam, L., 2001. The Precious Treasury of the Basic Space of Phenomena. Junction City, CA: Padma Publishing.

Rabjam, L., 2007. The Precious Treasury of Philosophical Systems. Junction City: Padma Publishing.

Raffone, A., Srinivasan, N., 2009. An adaptive workspace hypothesis about the neural correlates of consciousness: insights from neuroscience and meditation studies. Progress in Brain Research 176, 9 , 17620-3.

Raichle ME. The restless brain: how intrinsic activity organizes brain function. Philos Trans $\mathrm{R}$ Soc Lond $\mathrm{B}$ Biol Sci. 2015 May 19;370(1668):20140172. doi: 10.1098/rstb.2014.0172

Rangdrol, T.N., 1990. The Circle of the Sun. Hong Kong: Rangjung Yeshe. 
Ricard, M., Singer, W., 2017. Beyond the Self: Conversations Between Buddhism and Neuroscience. Cambridge: The MIT Press.

Roach JP, Pidde A, Katz E, Wu J, Ognjanovski N, Aton SJ, Zochowski MR. Resonance with subthreshold oscillatory drive organizes activity and optimizes learning in neural networks. Proc Natl Acad Sci U S A. 2018 Mar 27;115(13):E3017-E3025. doi: 10.1073/pnas.1716933115.

Rosenthal D. Higher-order awareness, misrepresentation and function. Philos Trans R Soc Lond B Biol Sci. 2012 May 19;367(1594):1424-38. doi: 10.1098/rstb.2011.0353.

Sadaghiani S, D'Esposito M. Functional Characterization of the Cingulo-Opercular Network in the Maintenance of Tonic Alertness. Cereb Cortex. 2015 Sep;25(9):2763-73. doi: 10.1093/cercor/bhu072.

Sadaghiani, S., \& Wirsich, J. (2020). Intrinsic connectome organization across temporal scales: New insights from cross-modal approaches. Network Neuroscience, 4(1), 1-29. doi.org/10.1162/ netn_a_00114

Saggar, M., Zanesco, A.P., King, B.K., 2015. Longitudinal mean-field modeling of thalmocortical interactions associated with intensive meditation training based on changes in scalp-recorded EEG. Neuroimage, 114, 88-104.

Scheeringa R, Fries P. Cortical layers, rhythms and BOLD signals. Neuroimage. 2019 Aug 15;197:689-698. doi: 10.1016/j.neuroimage.2017.11.002.

Schiff ND. Recovery of consciousness after brain injury: a mesocircuit hypothesis. Trends Neurosci. 2010 Jan;33(1):1-9. doi: 10.1016/j.tins.2009.11.002.

Schoenberg, P.L.A., Ruf, A., Churchill, J., et al. 2018. Mapping complex mind states: EEG neural substrates of meditative unified compassionate awareness. Consciousness and Cognition, 57, 41-53.

Shea N. Representation in Cognitive Science 2018 Oxford University Press.

Shea N, Frith CD. Dual-process theories and consciousness: the case for 'Type Zero' cognition. Neurosci Conscious. 2016 May 9;2016(1):niw005. doi: 10.1093/nc/niw005.

Sheffield JM, Barch DM. Cognition and resting-state functional connectivity in schizophrenia. Neurosci Biobehav Rev. 2016 Feb;61:108-20. doi: 10.1016/j.neubiorev.2015.12.007. Epub 2015 Dec 14. PMID: 26698018;

Spreng RN, Gerlach KD, Turner GR, Schacter DL. Autobiographical Planning and the Brain: Activation and Its Modulation by Qualitative Features. J Cogn Neurosci. 2015 Nov;27(11):2147-57. doi:

10.1162/jocn_a_00846

Srinivasan N. Consciousness Without Content: A Look at Evidence and Prospects. Front Psychol. 2020 Aug 7;11:1992. doi: 10.3389/fpsyg.2020.01992. 
Storm JF, Boly M, Casali AG, Massimini M, Olcese U, Pennartz CMA, Wilke M. Consciousness Regained: Disentangling Mechanisms, Brain Systems, and Behavioral Responses. J Neurosci. 2017 Nov 8;37(45):10882-10893. doi: 10.1523/JNEUROSCI.1838-17.2017.

Tanabe S, Huang Z, Zhang J, Chen Y, Fogel S, Doyon J, Wu J, Xu J, Zhang J, Qin P, Wu X, Mao Y, Mashour GA, Hudetz AG, Northoff G. Altered Global Brain Signal during Physiologic, Pharmacologic, and Pathologic States of Unconsciousness in Humans and Rats. Anesthesiology. 2020 Jun;132(6):1392-1406. doi: 10.1097/ALN.0000000000003197.

Tang, Y.Y., B.K. Holzel \& M.I. Posner. 2015. The neuroscience of mindfulness meditation. Nat. Rev. Neurosci. 16: 213-225.

Thompson E. 2014. Waking, Dreaming, Being: New Light on the Self and Consciousness from Neuroscience, Meditation, and Philosophy. New York: Columbia University Press.

Thompson, E. What's in a Concept? Conceptualizing the Nonconceptual in Buddhist Philosophy and Cognitive Science. in Christian Coseru, ed., Reasons and Empty Persons: Mind, Metaphysics, and Morality: Essays in Honor of Mark Siderits. London: Springer, 2021.

Tomasi, D., Volkow, N.D., 2011. Functional connectivity hubs in the human brain. Neuroimage, 57, 908917.

Tononi, G., and Koch, C. (2015). Consciousness: here, there and everywhere?

Philos. Trans. R. Soc. Lond. Ser. B Biol. Sci. 370:20140167. doi: 10.1098/rstb.2014.0167

Travis, F., and Pearson, C. (2000). Pure consciousness: distinct phenomenological and physiological correlates of "consciousness itself". Intern. J. Neurosci. 100, 77-89. doi: 10.3109/00207450008999678

Utevsky, A.V., Smith, D.V. Huettel, S.A., 2014. Precuneus Is a Functional Core of the Default-Mode Network. The Journal of Neuroscience, 34, 3, 932-940.

Van Lente E and Hogan MJ (2020) Understanding the Nature of Oneness Experience in Meditators Using Collective Intelligence Methods. Front. Psychol. 11:2092. doi: 10.3389/fpsyg.2020.02092

Vogt, B.A., Laureys, S., 2005. Posterior cingulate, precuneal and retrosplenial cortices: cytology and components of the neural network correlates of consciousness. Progress in Brain Research, 150, 205217.

Voss, U., Holzmann, R., Hobson, A. et al. Induction of self awareness in dreams through frontal low current stimulation of gamma activity. Nat Neurosci 17, 810-812 (2014).

https://doi.org/10.1038/nn.3719

Webb, T.W., Graziano, M.S., 2015. The attention schema theory: a mechanistic account of subjective awareness, Frontiers in Psychology, 6, 1-11.

Williams, P., 2000. The Reflexive Nature of Awareness. New Delhi: Motilal Banarsidass. 
Windt, J. M. (2015). "Just in time-dreamless sleep experience as pure subjective temporality" in Open MIND. eds. T. K. Metzinger and J. M. Windt Frankfurt am Main: MIND Group. doi:

$10.15502 / 9783958571174$

Winter U, LeVan P, Borghardt TL, Akin B, Wittmann M, Leyens Y, Schmidt S. Content-Free Awareness: EEG-fcMRI Correlates of Consciousness as Such in an Expert Meditator. Front Psychol. 2020 Feb 18;10:3064. doi: 10.3389/fpsyg.2019.03064.

Wu GR, Di Perri C, Charland-Verville V, Martial C, Carrière M, Vanhaudenhuyse A, Laureys S, Marinazzo D. Modulation of the spontaneous hemodynamic response function across levels of consciousness. Neuroimage. 2019 Oct 15;200:450-459. doi: 10.1016/j.neuroimage.2019.07.011.

Yaden, D. B., Haidt, J., Hood, R. W., Jr., Vago, D. R., \& Newberg, A. B. (2017, May 1). The Varieties of Self-Transcendent Experience. Review of General Psychology. Advance online publication. http://dx.doi.org/10.1037/gpr0000102

Zahidi, K. Non-representationalist cognitive science and realism. Phenom Cogn Sci 13, 461-475 (2014). https://doi.org/10.1007/s11097-013-9310-6

Zhang, S., Li, C., 2012. Functional connectivity mapping of the human precuneus by resting state fMRI. Neurolmage, 59, 4, 3548-3562.

Zheng A. Montez DF. Dosenbach NUF. Parallel Hippocampal-Parietal Circuits for Self and Goal-oriented Processing 2020. bioRxiv preprint doi: https://doi.org/10.1101/2020.12.01.395210; 